\title{
Advancing text prediction skills through translanguaging
}

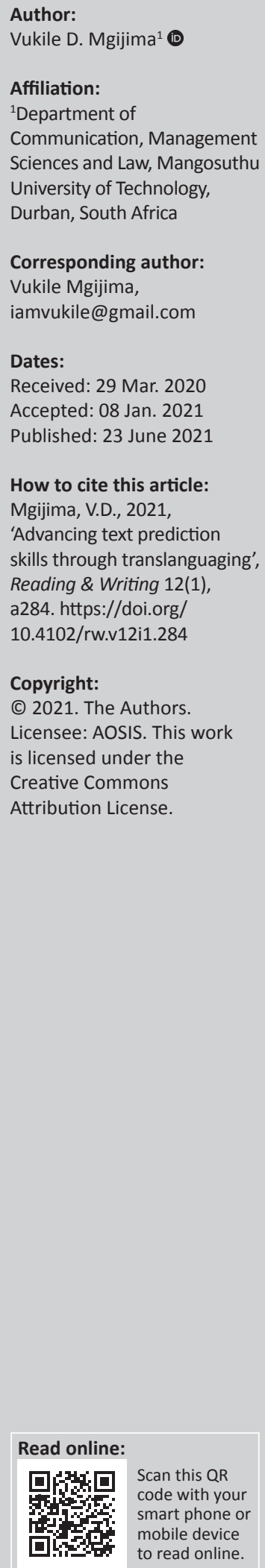

Background: Making predictions on how events might unfold when reading a text improves comprehension. Research on reading and making predictions tends to focus predominantly on the effects of making predictions as a reading strategy in monolingual contexts. So far, there is a paucity of research on the effects of reading development strategies in which learners are encouraged to read a text and express their predictions on how the events might unfold in the text in a different language from the one the text is written in.

Objectives: This study investigated the possible effects of translanguaging techniques on the readers' ability to make plausible predictions of events when reading texts.

Method: The study adopted a Solomon Four quasi-experimental design in which a total of 215 Grade 4 bilingual isiXhosa and English learners from different primary schools participated.

Results: The findings demonstrated that translanguaging techniques, in which a tapestry of the learners' linguistic repertoire is used simultaneously in one reading lesson, have a positive impact on the learners' ability to make plausible predictions on how the events might unfold when reading texts. The findings also indicated that accurate text prediction is determined by a number of factors, which include the reader's familiarity with the content, the context of the reading text and the vocabulary used therein.

Conclusion: For text prediction as a reading development strategy to be successful, the text and the reader's knowledge of the word, the world and the language ought to match. Otherwise, text prediction may be hampered due to lack of the reader's relevant background and linguistic knowledge.

Contribution: This article fills out the research gap that has been caused by limited research on the effects of translanguaging on the text prediction abilities of multilingual learners. It contributes significantly to the body of research by providing some of the strategies that multilingual learners can utilise to enhance their reading comprehension.

Keywords: text prediction; translanguaging; reading comprehension; Solomon Four; multilingualism.

\section{Introduction}

Reading is one of the essential skills that empower learners to meet their most vital needs and enhances meaningful participation in the social, cultural, political and economical domains of their community. However, it has been observed that the reading development of multilingual learners in elementary grades in South Africa often leads to poor performance and results in learners who struggle to read for meaning (DBE 2014; Howie et al. 2017).

Although there might be a number of reasons for this lack in reading ability (Modisaotsile 2012), the reasons they are not receiving much attention include the dominance of monolingual approaches employed to teach reading in multilingual communities. This study sought to investigate the effects of translanguaging, a teaching strategy that employs a tapestry of the learners' linguistic repertoire, on Grade 4 multilingual learners' ability to make predictions when reading texts. Making predictions on how events might unfold when reading a text improves comprehension (Roit 2016). Thus far, however, there is limited research that focuses on the effects of translanguaging on reading and text prediction in multilingual contexts.

The study responds to the following question: how effective is translanguaging on the text prediction skills of learners who have been trained to apply it to make predictions on how events might unfold when reading a narrative text? 


\section{Translanguaging}

This article adopted a translanguaging framework to address the text prediction abilities of the learners. Translanguaging is an umbrella term used to refer to a communication encounter in which multilingual interlocutors engage various semiotic means to express thoughts. The concept, which is attributed to Cen Williams (Baker, Jones, \& Lewis, 2012; Hornberger \& Link 2012), also refers to a pedagogical practice in a multilingual context in which learners receive input in one language and give output in a different one. In essence, it strikes a balance between the learners' language deficiency and content learning, in that the learners are allowed to utilise the variety of languages at their disposal to interact with the teacher, the content and with each other in a learning process. For instance, one can read a text in one language and retell or explain it in another. Thus, translanguaging is an apolitical transformational tapestry of sense-making mechanisms that a multilingual person engages in to communicate.

Various models through which translanguaging can be incorporated as a pedagogical approach have been proposed. These include Hornberger's continua of biliteracy (Hornberger \& Link 2012) and Makalela's ubuntu translanguaging (Makalela 2016) models. The continua of a biliteracy lens posits that learning occurs at various intersections along and across continua at which one's knowledge and use of different language varieties and literacies meet. The continua enable one to see how possible it is for infinite, elusive, unpredictable, interrelated and simultaneous opportunities for literacy to develop within the continua, taking into account various contexts, content, linguistic and literacy repertoires that learners bring to the learning environment. According to Hornberger and Link (2012):

\footnotetext{
... the continua of biliteracy lens reminds educators that the more students' contexts of language and literacy use allow them to draw from across the whole of each and every continuum, the greater are the chances for their full language and literacy development and expression. (p. 243)
}

At the centre of the continua of biliteracy are multilingualism as a resource, and translanguaging as a vehicle through which biliteracy can be achieved. Therefore, as a framework within which a study can be conceptualised, translanguaging presents a positive angle from which multilingualism should be researched.

Makalela (2016) proposes a model in which an African value system of interdependency, ubuntu, is the framework for translanguaging. The model is introduced through a scenario about international trade and the co-existence of numerous language groups in the Limpopo valley to show the notion of confluence of African multilingualism. It shows how confluent, fluid and porous languages have become and questions the relevance of the separatist orientation towards language education and literacy development in the 21st century. The ubuntu lens fits well as a pedagogical strategy in a multilingual context since, in an African multilingual context for example, one language is not enough to complete the cycle of meaning-making. This, therefore, explains why 'the notion of translanguaging fits in to account for complex multilingual encounters where speakers use more than one language for exchange of input and output' (Makalela 2016:190)

It is noteworthy, though, that translanguaging is quite a recent concept whose theoretical underpinnings are still emerging. Nonetheless, there is a growing body of research that demonstrates positive effects of translingual interplay between home and school literacy practices worldwide. For instance, translanguaging has been broadened to include multiple discursive language practices (García 2009) and semiotic repertoires (Wei 2018), including technology (Vogel, Ascenzi-Moreno \& García 2018), wherein a multilingual person engages in a communication process. Thus, a translanguaging framework fits this study since the participants were encouraged to read a text in one language and give their predictions on how the events might unfold in the text in another language.

\section{Enhancing reading ability through text prediction}

Previous studies show that encouraging learners to engage in making predictions when reading texts increases reading interest and comprehension (Block \& Duffy 2008; Duke \& Pearson 2004). Making predictions involves forming hypotheses about what will happen next, or what ideas the text will advance, followed by continuous evaluation of these predictions and hypotheses and revising them as the reading warrants (Roit 2016). The process employs a great deal of relevant existing knowledge on the topic. However, one might need to exercise due diligence when making predictions about a reading text since each text is unique and, thus, calls for specific prior knowledge. The knowledge facilitates understandings of the ideas as the reader interacts with the text.

Duke and Pearson (2004) provide some of the practical examples of what a teacher should do to enhance text prediction skills of learners. They suggest that before reading a story, students should be encouraged to generate expectations about what the characters might do, based on their (the reader's) own experiences in similar situations. In essence, studies suggest that encouraging learners to engage their knowledge and experience prior to reading can be productive in various ways. For instance, a reader brings to the reading process their experience, knowledge of the language and thought development, which aid their ability to anticipate that which has not yet been stated in the reading - the reader's expectation. This observation concurs with Goodman and Goodman's (1976) view about reading, according to which reading is viewed as a psycholinguistic guessing game in which a reader selectively processes new information using knowledge of available language cues to arrive at a decision. In this manner, reading becomes an 
interactive meaning-making process between the reader and the text in which a readers, as Block and Duffy (2008) put it:

... proactively search for meaning as they read, using text cues and their background knowledge in combination to generate predictions, to monitor those predictions, to repredict when necessary, and generally to construct a representation of the author's meaning. (p. 21)

In addition, McIntyre, Hulan and Layne (2011) suggest two ways in which a teacher can enhance the learners' ability to make predictions when reading texts, which are: using a 'take a picture walk' and an anticipation guide. With regard to 'take a picture walk', McIntyre et al. (2011) suggest that before reading, a teacher can allow time for the learners to view the pictures and illustrations in the text, and then make predictions based on what they see. The teacher can also use an anticipation guide, in which the learners can indicate whether statements that make predictions about the text to be read are true or false. This can be taken as a true-false quiz before, during and after reading. As the learners read the text they can check their answers, and change them accordingly as the reading progresses.

Encouraging learners to make predictions when reading texts fosters comprehension, keeps the reader actively engaged and improves reading ability. It also allows the reader to go beyond the text and construct a richer understanding of the reading text (Allbritton 2004). Therefore, reading comprehension is a fluid interactive process in which a reader obtains information from the text, makes predictions on how the events might unfold, monitors their predictions, and then re-predicts in a continuous cycle. To comprehend, the reader must use the text cues at their disposal to predict, monitor their prediction as they continue reading the text, and revisit their predictions to check for accuracy. For prediction to be successful as a comprehension strategy, the reader ought to know how to predict, monitor and revise their predictions in due time and due parts during their reading.

As may have been noticed in the foregoing review, research on reading and making predictions tends to focus predominantly on the effects of making predictions as a reading strategy in monolingual contexts. So far, there is a paucity of research on the effects of reading development strategies in which learners are encouraged to read a text and express their predictions on how the events might unfold in the text in a different language from the one the text is written in. This study, therefore, investigated the effects of translanguaging on the reader's ability to make predictions as one of the comprehension strategies when reading texts.

\section{The study}

This study adopted a Solomon Four quasi-experimental design. A Solomon Four design is a pre-test-post-test experimental design. It is similar to other experimental designs in that it has randomised groups, all of which get post-tested. Conversely, the design differs from other pretest-post-test experimental designs in that it has two pretested experimental groups, one of which gets treatment, and two post-tested control groups that have not been pretested, one of which gets treatment. In other words, this design allows one to have four groups comprising two experimental groups (herein, groups A \& B), which receive treatment or intervention, and two control groups (herein, groups C \& D) that do not. In this study, a translanguaging intervention was administered, in which two languages, isiXhosa, which is the participants' home language, and English, their first additional language, were used simultaneously in the same lesson.

A total of 215 Grade 4 learners in four different rural schools in quintile 2 in one district in the Eastern Cape participated in the study. Rural schools were preferred for the study because they often perform the lowest according to the annual national assessment reports (see DBE 2014), and need more support to advance quality education. Purposive sampling was used to select the schools. The schools whose learners participated in the study were chosen based on their shared characteristics. The schools were ranked quintile 2. Schools ranked quintile 2 are mostly rural and have learners from disadvantaged backgrounds measured by the socio-economic conditions and literacy rate of the surrounding communities in which the schools are situated. A quintile 1 ranking indicates an impoverished school, while a quintile 5 indicates an affluent school (Van Dyk \& White 2019). Learners in schools classified as quintile 2 are exempted from paying school fees, and are provided with meals at school. Quintile 2 schools are the poorest of the schools while quintile 5 schools are rich schools that cater for learners from financially affluent families. This quintile ranking of schools determines the financial status of the school for budget allocation and government funding. It is noteworthy that learners in poor and rural districts are more disadvantaged, and that learners in these areas tend to perform at a level lower to that of learners in urban areas due to, inter alia, lack of resources.

The schools whose learners participated in the study were also chosen on the basis of the languages used for teaching and learning from Grade R to Grade 3 - isiXhosa, which is supposed to be the home language of all or most of the learners at the school, and the learners must be transitioning into English as the language of teaching and learning in Grade 4. Both English (as first additional language) and isiXhosa (as mother tongue) were offered at the schools in Grade 4 . The schools were randomly assigned to different groups, with the first two schools whose names starts with a letter closest to ' $\mathrm{A}$ ' assigned to the control groups, while the other two were assigned to the experimental groups.

Data were collected through a battery of tests which contained a mixture of multiple choice and open-ended questions. The participants attempted two sets of pre-tests and post-tests: one set was in their home language, while another was in English. Each set had two different reading passages of about 
300 words, followed by comprehension questions. The passages were curriculum-based fictional narratives about animals. To ensure the quality and the appropriate level of the language in the passages, a readability test was run on the English passages using online readability tests (Readability Formulas 2017). Both the isiXhosa and English texts were examined by language specialists for appropriateness and were found to be reader-friendly and suitable for Grade 4 learners. A total of 15 comprehension questions in each language were set. For the purposes of this study, much attention was paid to two questions that assessed the participants' ability to make predictions on how the events might unfold in the text.

\section{Ethical considerations}

Permission to conduct research from which this article came was obtained from the Eastern Cape Department of Education in 2017.

\section{Intervention}

The intervention was administered to the treatment groups (Groups A \& B) during the participants' scheduled regular class time and in the regular classrooms used for teaching English and isiXhosa as subjects during their usual periods. Four language teachers who taught in the two experimental schools were briefed on translanguaging and what it entailed as a pedagogical approach. They were involved in developing lesson plans on teaching reading in more than one language simultaneously in the same class. During the induction process, the researcher demonstrated how one could use more than one language simultaneously in one classroom. More attention was paid to how to use translanguaging methods to teach learners to make predictions when reading texts. After the training, the teachers were provided with lesson plans and stories they could use to implement the initiative as suggested.

The treatment was introduced a day after the learners had written the pre-tests. The researcher remained available to provide guidance at the first experimental group site, while the teachers who had been trained in the approach provided the intervention to the second experimental group in a different school.

Learners were provided with one reading passage in which both isiXhosa and English had been used. The passages that were used for the translanguaging treatment were curriculum-based fictional narratives that had been obtained from the learners' textbooks. Before reading, learners were encouraged to make predictions about the text to be read, including what they thought the text would be about, based on the clue words that were written on the board at the beginning of the class.

Reading was done in an interactive way in which the teacher read the text aloud while the learners read along silently. At some point during the reading, the teacher asked the learners to take turns reading the text aloud while the rest of the class was reading along silently. During the exercise, the teacher often checked with the learners to verify or redirect their predictions. This was done in a dialogical way in which the teacher asked questions to get learners to respond to or think about the predictions they made at the beginning of the reading.

Questions, answers of which could be located in paragraphs that were written in English, were asked in isiXhosa, and vice versa. Thus, translanguaging methods were used to explicitly teach the learners how to read a text through the juxtaposition of the languages of input and output.

Think-aloud strategies were also used. To this effect, the teacher read the text aloud, paused at certain points and asked questions, answers of which could only be provided by making logical inferences. The teacher also verbalised their thinking in order to help learners make the correct inferences. This exercise explicitly showed how learners should make predictions when reading texts.

After the intervention, the participants were assessed on their ability to make predictions when reading texts.

Even though a translingual approach in which the input and output languages were juxtaposed was used during the intervention, the participants were required to respond to test questions in the language the questions were asked in. That is, for the English reading test, the participants had to respond in English, while the same was held for isiXhosa. This was done in order to be in line with the current standard practice in formal academic assessments in which a test-taker has to respond in the same language in which the assessment questions have been asked.

\section{Data presentation}

Presented below are the processes followed to analyse the data in order to make findings. The findings were tested against the null hypothesis which posited that the performance of the participants regarding the target ability would remain the same in both languages and in all groups of participants regardless of the intervention.

\section{Making predictions in isiXhosa}

The participants in the first experimental (Group A) and control (Group C) groups were assessed on their ability to make plausible predictions on how the events might unfold in the texts they read. For isiXhosa home language, the posttest results indicated an improved performance for the two groups. The participants in the first experimental group (Group A) displayed much more improvement than those in the control. The descriptive measures of central tendencies and dispersion of the results of this assessment are presented in Table 1.

Table 1 displays the mean scores of the participants from the first experimental group (Group A) and the first control 
TABLE 1: Making predictions in isiXhosa

\begin{tabular}{|c|c|c|c|c|c|c|c|c|c|c|c|c|c|}
\hline \multirow[t]{2}{*}{ Variable } & \multicolumn{5}{|c|}{ Experimental group A } & \multicolumn{5}{|c|}{ Control group C } & \multicolumn{3}{|c|}{ Total } \\
\hline & Pre-test & Post-test & $t$ & $d f$ & $p$ & Pre-test & Post-test & $t$ & $d f$ & $p$ & $t$ & $d f$ & $p$ \\
\hline Mean & 1.48 & 1.64 & - & - & - & 1.13 & 1.20 & - & - & - & - & - & - \\
\hline$N$ & 54 & 50 & - & - & - & 32 & 35 & - & - & - & - & - & - \\
\hline Standard deviation & 0.64 & 0.63 & - & - & - & 0.94 & 0.83 & - & - & - & - & - & - \\
\hline Values & - & - & 1.420 & 49 & $>0.05$ & - & - & 0.296 & 23 & $>0.05$ & 4.116 & 31 & $<0.05$ \\
\hline
\end{tabular}

group (Group C) on their ability to make predictions on how the events would unfold when reading texts in isiXhosa home language. It shows that the participants in the first experimental group (Group A) obtained a mean score of 1.48 and a standard deviation of 0.64 in the pre-test, and 1.64 with a standard deviation of 0.63 in the post-test. With the standard deviation lower than the mean for each assessment, the level of homogeneity with regard to the ability to make predictions on how the events would unfold when reading texts in isiXhosa was strong in both the pre-test and the post-test. In other words, the scores of most of the participants could be located around a central point. At face value, the mean scores of the two tests show that the participants performed better in the post-test than they did in the pre-test. To verify this assumption, the pre-test and post-test scores were run in a $t$-test. The results of the $t$-test reflected a statistically nonsignificant difference at an alpha value of $0.05(t=1.420 ; d f=$ $49 ; p>0.05)$. In other words, even though there is some difference between the mean scores of the pre-test and the post-test within this group, the difference is too marginal to be considered statistically existent. Therefore, this accepts the null hypothesis which posited that performance of the participants on making plausible predictions regarding the events in the text would remain the same regardless of the intervention. The fact that the results of the $t$-test reflected a statistically non-significant difference also implies that the difference in the performance between the two assessments should be viewed with caution, because there might be a shadow on the researcher's overall results.

With regard to the first control group (Group C), Table 1 shows that the group obtained a mean of 1.13 with a standard deviation of 0.94 in the pre-test, and 1.20 with a standard deviation of 0.83 in the post-test. Since the mean score for each assessment was higher than its standard deviation, the group was deemed homogenous. The results of the $t$-test reflected that the difference between the pretest and the post-test was statistically non-significant at an alpha value of $0.05(t=0.296 ; d f=23 ; p>0.05)$. This, therefore, accepts the null hypothesis which posited that performance of the participants on the ability to make predictions would remain the same between the pre-test and the post-test. The fact that the results of the $t$-test reflected that the difference between the pre-test and the post-test was statistically non-significant also implies that the difference in the performance between the two assessments should be viewed with caution, because there might be a shadow on the researcher's overall results.

The post-test scores of the first experimental (Mean $[M]=$ 1.64; standard deviation $[\mathrm{SD}]=0.63$ ) and the first control
TABLE 2: Making predictions in isiXhosa post-test.

\begin{tabular}{lccccc}
\hline Variable & $\begin{array}{c}\text { Experimental } \\
\text { group B }\end{array}$ & $\begin{array}{c}\text { Control } \\
\text { group D }\end{array}$ & $\boldsymbol{t}$ & $d f$ & $\boldsymbol{p}$ \\
\hline Mean & 0.88 & 1.33 & - & - & - \\
$N$ & 24 & 98 & - & - & - \\
Standard deviation & 0.90 & 0.77 & - & - & - \\
Value & - & - & 1.390 & 34 & $>0.05$ \\
\hline
\end{tabular}

$(M=1.20 ; \mathrm{SD}=0.83)$ groups were tested via a $t$-test to measure their variability. The results revealed that the differences between the two groups were statistically significant at an alpha value of $0.05(t=4.116 ; d f=31$; $p<0.05)$. The null hypothesis, which predicted no variability between the two groups, was therefore rejected.

An analysis was also run between the second experimental (Group B) and control (Group D) groups. Table 2 shows the results of the two groups.

Concerning the groups that wrote the post-test only, the second experimental (Group B) and control (Group D) groups, it was observed that the second experimental group obtained a mean score of 0.88 and a standard deviation of 0.90 , while the second control obtained a mean score of 1.33 and a standard deviation of 0.77 . The second control group (Group D) performed better than the second experimental group (Group B), because its mean was higher. The scores of the two groups were tested via $t$-test. The $t$-test results of the two groups indicated a statistically non-significant difference at an alpha value of $0.05(t=1.390 ; d f=34 ; p>0.05)$ and, therefore, accepts the null hypothesis. The statistically nonsignificant difference reflected by the $t$-test results implies that the difference in the performance between the two groups should be viewed with caution since there might be a shadow on the researcher's overall results.

A one-way analysis of variance (ANOVA) was run on the post-test scores obtained from the four groups (i.e. groups A, B, C \& D) to measure the significance of the variance between the four groups' performances on making predictions on how the events would unfold when reading texts in isiXhosa. Table 3 shows the results of the ANOVA in which variance in performance within each of the groups that wrote the pre-test and the post-test (i.e. groups A \& C), and between the four groups, was measured.

The results of the ANOVA displayed an $f$-ratio value of 3.65804 , and a $p$-value of 0.013319 . Therefore, the differences in the performance between the four groups were statistically significant at an alpha value of $0.05 .(f=3.65804 ; d f=3$; $p<0.05)$. Thus, the null hypothesis which predicted that 
there would be no difference in the performance between the four groups was rejected.

\section{Making predictions in English}

Concerning English first additional language, the post-test results indicated improved performance on the first experimental (Group A) and the control (Group C) groups. The descriptive measures of central tendencies and dispersion of the results of this assessment are presented in Table 4.

Table 4 shows the mean scores of the participants from the first experimental group (Group A) and the first control group (Group C) on their ability to make predictions on how the events would unfold when reading texts in English first additional language. Table 4 shows that the participants in the first experimental group (Group A) obtained a mean score of 0.51 with a standard deviation of 0.86 in the pre-test, and 0.94 with a standard deviation of 0.90 in the post test. The table also indicates that the group was not homogenous at pre-test, hence the mean was higher than the standard deviation. The post-test results of the first experimental group (Group A) showed some improved performance, since the mean score of the post-test was higher than the pre-test and the standard deviation was lower than the mean. The differences between the pre-test and the post-test results were tested via a $t$-test. The results revealed that the differences between the two assessments were statistically significant at an alpha value of $0.05(t=2.079 ; d f=50 ; p<0.05)$. The null hypothesis, which predicted that there would be no difference in the performance between the two assessments, was therefore rejected. This implies that the translanguaging techniques were effective in inducing the participants' ability to make predictions on how the events would unfold when reading texts in English first additional language.

With regard to the first control group (Group C), the participants obtained a mean score of 0.58 with a standard deviation of 0.96 in the pre-test, and 1.33 with a standard deviation of 1.12 in the post-test. The post-test results indicated some improvement in the performance of the participants since the mean of the post-test was higher. Furthermore, the dispersion level for each test was lower than its mean score, which indicated that the group was homogenous. The results of the two assessments were

TABLE 3: Analysis of variance results on making predictions in isiXhosa.

\begin{tabular}{lccccc}
\hline Variable & Sum of squares & $\boldsymbol{d f}$ & Mean square & $\boldsymbol{F}$ & $\boldsymbol{P}$ \\
\hline Between treatments & 6.6662 & 3 & 2.2221 & 3.65804 & 0.013319 \\
Within treatments & 128.171 & 211 & 0.6074 & - & - \\
\hline Total & $\mathbf{1 3 4 . 8 3 7 2}$ & $\mathbf{2 1 4}$ & - & - & - \\
\hline
\end{tabular}

measured in a $t$-test. The results of the $t$-test reflected a statistically non-significant difference between the pre-test and the post-test at an alpha value of $0.05(t=0.297 ; d f=29$; $p>0.05)$. Therefore, the null hypothesis, which predicted that there would be no difference in the performance between the two tests, was confirmed. This implies that the difference in the performance between the two assessments should be viewed with caution, because there might be a shadow on the researcher's overall results.

According to the results of the first experimental $(M=0.94$; $\mathrm{SD}=0.90)$ and the first control $(M=1.33 ; \mathrm{SD}=1.12)$ groups, the groups that had attempted a pre-test and a post-test were analysed to measure the level of comparability. To this effect, a $t$-test was run. The results reflected that the two groups were statistically significant at an alpha value of $0.05(t=2.232$; $d f=30 ; p \leq 0.05)$. This implies that the null hypothesis which predicted that there would be no difference between the two groups, regardless of the intervention, was rejected.

An analysis was also run between the second experimental (Group B) and the second control (Group D) groups. Table 5 shows the results of the two groups.

Concerning the groups that did not write the pre-test, which were the second experimental (Group B) and the second control (Group D) groups, the results indicated that the second experimental group (Group B) obtained a mean score of 0.67 with a standard deviation of 0.80 , while the second control group (Group D) obtained a mean score of 0.42 with a standard deviation of 0.74 . Each group was deemed heterogeneous since the standard deviation for each was higher than the mean. However, the second experimental group (Group B) performed better than the second control group (Group D), hence the mean of the former is higher. The $t$-test results of the two groups reflected a statistically significant difference between the two groups at an alpha value of $0.05(t=4.356 ; d f=29 ; p<0.05)$. Therefore, the null hypothesis which predicted that there would be no difference between the two groups due to the intervention was rejected.

A one-way ANOVA was run on the post-test scores obtained from the four groups (i.e. groups A, B, C \& D) to measure the

TABLE 5: Making predictions in English - post-test.

\begin{tabular}{lccccc}
\hline Variable & $\begin{array}{c}\text { Experimental } \\
\text { group B }\end{array}$ & $\begin{array}{c}\text { Control } \\
\text { group D }\end{array}$ & $\boldsymbol{t}$ & $d f$ & $\boldsymbol{p}$ \\
\hline Mean & 0.67 & 0.42 & - & - & - \\
$N$ & 30 & 95 & - & - & - \\
Standard deviation & 0.80 & 0.74 & - & - & - \\
Value & - & - & 4.356 & 29 & $<0.05$ \\
\hline
\end{tabular}

TABLE 4: Making predictions in English.

\begin{tabular}{|c|c|c|c|c|c|c|c|c|c|c|c|c|c|}
\hline \multirow[t]{2}{*}{ Variable } & \multicolumn{5}{|c|}{ Experimental group A } & \multicolumn{5}{|c|}{ Control group C } & \multicolumn{3}{|c|}{ Total } \\
\hline & Pre-test & Post-test & $t$ & $d f$ & $p$ & Pre-test & Post-test & $t$ & $d f$ & $p$ & $t$ & $d f$ & $p$ \\
\hline Mean & 0.51 & 0.94 & - & - & - & 0.58 & 1.33 & - & - & - & - & - & - \\
\hline$N$ & 51 & 54 & - & - & - & 31 & 30 & - & - & - & - & - & - \\
\hline Standard deviation & 0.86 & 0.90 & - & - & - & 0.96 & 1.12 & - & - & - & - & - & - \\
\hline Value & - & - & 2.079 & 50 & $<0.05$ & - & - & 0.297 & 29 & $>0.05$ & 2.232 & 30 & $<0.05$ \\
\hline
\end{tabular}


significance of the variance between the four groups performances on the ability to make predictions on how events would unfold when reading texts in English. Table 6 shows the results of the ANOVA in which variance in performance within each of the groups that wrote the pre-test and the post-test (i.e. groups A \& C), and between the four groups was measured.

The results of the ANOVA displayed an $f$-ratio value of 10.01516 , and a $p$-value of 0.00001 . Therefore, the differences in the performance between the four groups were statistically significant at an alpha value of $0.05(f=10.01516 ; d f=3 ; p<$ 0.05). Thus, the null hypothesis which predicted that there would be no difference in the performance between the four groups was rejected.

\section{A comparison of the ability to make plausible predictions between English and isiXhosa}

To refine the extent of the influence of translanguaging on making plausible predictions, the scores of the first and the second experimental groups were combined to form a grand score, and further analyses were conducted on them. The same was done with the control group scores. The results each group obtained for each language were compared within and between the groups to measure the influence of translanguaging on the target ability between the two languages. Table 7 displays the post-test results in which the two languages were compared within each of the groups.

Table 7 shows that the participants in the experimental groups scored a grand mean of 1.43 with a standard deviation of 0.74 in isiXhosa, whereas they obtained a grand mean score of 0.61 with a standard deviation of 0.84 in English. With regard to isiXhosa, the grand mean (1.43) is higher than that of English (0.84). The standard deviation is lower than its grand mean in isiXhosa, while it is higher than the grand mean in English. This suggests that the participants in the experimental groups were fairly homogenous in their home language while heterogenous in their first additional language. With regard to the control groups, the table shows that the groups obtained a grand mean score of 1.16 with a standard deviation of 0.88 in isiXhosa, while their grand mean was 0.95 with a standard deviation of 1.10 in English. As observed in the experimental groups, the grand mean in isiXhosa (1.16) is higher than that of English (0.95). The

\begin{tabular}{|c|c|c|c|c|c|}
\hline Variable & Sum of squares & $\overline{d f}$ & Mean square & $F$ & $P$ \\
\hline Between treatments & 23.0747 & 3 & 7.6916 & 10.01516 & 0.00001 \\
\hline Within treatments & 158.2063 & 206 & 0.768 & - & - \\
\hline Total & 181.281 & 209 & - & - & - \\
\hline
\end{tabular}

TABLE 7: A comparison on making predictions between English and isiXhosa.

\begin{tabular}{lccccc}
\hline Variable & \multicolumn{2}{c}{ Experimental groups } & & \multicolumn{2}{c}{ Control groups } \\
\cline { 2 - 3 } \cline { 5 - 6 } & isiXhosa & English & & isiXhosa & English \\
\hline Grand mean & 1.43 & 0.61 & & 1.16 & 0.95 \\
$N$ & 148 & 149 & & 67 & 61 \\
Standard deviation & 0.74 & 0.84 & & 0.88 & 1.10 \\
\hline
\end{tabular}

standard deviation is lower than its grand mean in isiXhosa, while it is higher than the grand mean in English. This suggests that the participants in the experimental groups were fairly homogenous in their home language while heterogenous in first additional language.

The results show that the level of homogeneity was stronger in isiXhosa than it was in English for both the experimental and the control groups, since the standard deviations in isiXhosa were the furthest from their grand means. With the highest grand mean and much stronger level of homogeneity of the two, the participants in the experimental groups performed better than those in the control groups when it comes to making predictions.

The scores obtained in each language were tested via a $t$-test to measure the variability between the two sets of groups. Table 8 shows a comparison of the grand mean scores and the results of the $t$-test on the ability to predict text between the experimental and control groups for isiXhosa.

Table 8 shows a comparison of the grand mean scores and the results of the $t$-test on the ability to predict text between the experimental and control groups for isiXhosa. The $t$-test results revealed that the differences between the two sets were statistically non-significant at an alpha value of $0.05(t=$ $2.318 ; d f=213 ; p>0.05)$. The null hypothesis, which predicted no variability in performance between the experimental and the control groups, was therefore confirmed. This implies that with regard to isiXhosa, there was insufficient evidence for one to attribute the difference in the performance to the translanguaging techniques employed.

Furthermore, the fact that the $t$-test results came out nonsignificant means that the difference in the performance between the two sets should be viewed with caution, because there might be a shadow on the researcher's overall results.

The English scores too were subjected to a $t$-test. Table 9 shows a comparison of the grand mean scores and the results

TABLE 8: A comparison of the grand mean scores and $p$-value on the ability to make text prediction in isiXhosa.

\begin{tabular}{lccccc}
\hline Variable & \multicolumn{2}{c}{ isiXhosa } & $t$ & $d f$ & $p$ \\
\cline { 2 - 4 } & Experimental groups & Control groups & & & \\
\hline Grand mean & 1.43 & 1.16 & - & - & - \\
$N$ & 148 & 67 & - & - & - \\
$\begin{array}{l}\text { Standard } \\
\text { deviation }\end{array}$ & 0.74 & 0.88 & - & - & - \\
Value & - & - & 2.318 & 213 & $>0.05$ \\
\hline
\end{tabular}

TABLE 9: A comparison of the grand mean scores and $p$-value on the ability to make text prediction in English.

\begin{tabular}{lccccc}
\hline Variable & \multicolumn{2}{c}{ English } & $t$ & $d f$ & $p$ \\
\cline { 2 - 4 } & Experimental groups & Control groups & & & \\
\hline Grand mean & 0.61 & 0.95 & - & - & - \\
$N$ & 149 & 61 & - & - & - \\
$\begin{array}{l}\text { Standard } \\
\text { deviation }\end{array}$ & 0.84 & 1.10 & - & - & - \\
Value & - & - & 1.159 & 208 & $>0.05$ \\
\hline
\end{tabular}


of the $t$-test on the ability to predict text between the experimental and control groups for English.

Table 9 shows a comparison of the grand mean scores and the results of the $t$-test on the ability to predict text between the experimental and control groups for English. The results indicated that the differences in performance between the two group sets were statistically significant at an alpha value of $0.05(t=1.159 ; d f=208 ; p>0.05)$. In this regard, the null hypothesis which had predicted that there would be no difference in the performance between the two group sets, regardless of the intervention, was therefore rejected. Thus, the difference in the performance as far as English was concerned could be attributed to the intervention administered.

At face value - looking at a higher grand mean and a stronger level of homogeneity - the results show that the participants in the experimental groups performed better in one language than they did in the other when it comes to predicting how the events would unfold in the text. To consolidate this assumption, the scores of the experimental groups were subjected to further $t$-tests to measure the extent of the difference in the performance between the first additional language and the home language. Table 10 shows a comparison of the grand mean scores and the results of the $t$-test of the experimental group on the ability to make predictions between isiXhosa and English.

The results indicate a statistically significant difference between the languages at an alpha value of $0.05(t=8.971 ; d f=295 ; p<$ $0.05)$. Thus, the null hypothesis which had predicted that there would be no difference in the performance between the two languages, regardless of the intervention, was rejected. This means that as far as the text prediction was concerned, translanguaging techniques were more effective in isiXhosa than they were in English.

TABLE 10: A comparison of the grand mean scores and $p$-value on the ability to predict text between isiXhosa and English.

\begin{tabular}{lccccc}
\hline Variable & \multicolumn{2}{c}{ Experimental groups } & $t$ & $d f$ & $p$ \\
\cline { 2 - 3 } & isiXhosa & English & & & \\
\hline Grand mean & 1.43 & 0.61 & - & - & - \\
$N$ & 148 & 149 & - & - & - \\
$\begin{array}{l}\text { Standard } \\
\text { deviation }\end{array}$ & 0.74 & 0.84 & - & - & - \\
Value & - & - & 8.971 & 295 & $<0.05$ \\
\hline
\end{tabular}

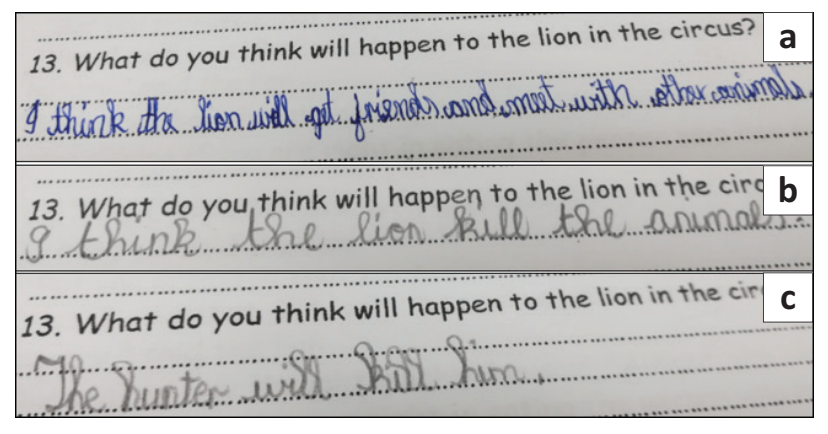

FIGURE 1: $(\mathrm{a}-\mathrm{c})$ Learner responses to a text prediction question.

\section{Findings incidental to the study}

Further analysis was run on the data to assess how the participants performed in the various types of questions in the test. The results revealed that the participants performed fairly well in multiple choice questions and in questions in which they were required to locate and retrieve information from the text. For instance, when asked what they thought would happen to the lion at the circus, some learners simply rewrote a sentence that mentioned the key word 'circus' as the answer (i.e. that the hunter came and took the lion away to the circus'). The fact that the learners rewrote the sentence that mentioned the key word shows that they did not understand the question. However, some who seemingly understood the question did not know what a circus is or what happens at it, as observed in the excerpt shown in Figure 1.

Figure 1 shows one of the questions in which learners were required to make predictions about how the events might unfold in the story. The results of the quantitative analysis showed that the participants exhibited an improved performance with regard to text prediction in English. However, the qualitative analysis exhibited that some of the learners may never have been to or heard of what happens at a circus. As a result, their predictions about what would happen to the lion at the circus were not accurate. What has been noted in the responses in the above excerpt (Figure 1), is that the learners understood the question but could not provide the expected correct answers due to lack of adequate background knowledge. It is noteworthy that the more students' contexts of language use and literacy allow them to draw from across the whole of their backgrounds, the greater are the chances for them getting and providing the answers correctly. As can be seen in the responses above, the readers' pre-existing knowledge related to the text content plays a pivotal role. Pre-existing knowledge helps readers compensate for gaps in text-based information by affording quick and relatively effortless access to relevant information in long-term memory, based on incomplete text-based information as cues. There are various ways in which prior knowledge can be activated to aid a reader to interact with the text and understand it better. These include asking a few questions to find out what the reader already knows about the topic and then providing the new knowledge that the reader might need (McIntyre et al. 2011). Since this was a formal assessment, at which a test-taker had to be silent, read on their own and attempt the test, it would be inappropriate to ask questions to check if the test-takers had sufficient background knowledge about the topic of the text content.

\section{Discussion}

The findings exhibited better comprehension of the text and the production of more relevant predictions on how the events might unfold. The results agree with other studies on comprehension and text prediction (see Duke \& Pearson 2004) in which the learners exhibited an enhanced reading performance, as a result of which the learners could, after 
making predictions, read without any teacher support. It is worth noting, however, that Duke and Pearson's study was conducted in a monolingual context in which their participants used one language to predict how the events would unfold in the text. In our case, the participants were trained on how they could use a tapestry of languages at their disposal to interact with texts. They, however, had to write in a language that was prescribed for assessment purposes.

It is noteworthy that the application of text prediction as one of the components of reading comprehension changes as a reader gets better at reading in terms of grade levels and text types. In other words, even though the strategy remains the same - that is: reading, making predictions, monitoring the predictions and revising them when necessary - a reader might need to adjust the strategy to suit the text type and the purpose for which the text is being read. According to Block and Duffy (2008), comprehension gets progressively more difficult from grade to grade. In this study, however, text prediction was kept at an elementary level in which the participants predicted what they thought would happen next, or what could happen if the scenario were different, due to the grade level of the participants. Nonetheless, making predictions on how the events might unfold as one reads a text has been shown to assist with comprehension as a reader reads, predicts and checks their predictions against the actual events in the reading.

Reading texts becomes more and more complex, and might require the predicting-monitoring-re-predicting cycle to be applied in more sophisticated ways that might necessitate more information, sufficient vocabulary and improved experience (McIntyre et al. 2011). What has been observed in this study is that the readers' background and related vocabulary is a contributory factor to text prediction when reading. Without sufficient background knowledge and vocabulary, a reader may have a hard time providing accurate predictions on how the events might unfold. Translanguaging allows a reader to draw from a whole range of their linguistic background, thus increasing their chances of making correct predictions. Therefore, it is recommended that, for text prediction as a reading development strategy to be successful, the text and the reader's knowledge of the word, the world and the language ought to match. Translanguaging is one of the pedagogies that enables knowledge of the word, the world and the language of a multilingual reader to match.

\section{Conclusion}

This article has demonstrated that translanguaging enhances text prediction abilities of multilingual learners.

It has been observed that the participants' ability to make plausible predictions on how the events would unfold in the text improved due to translanguaging. However, the participants' performance improved more significantly in isiXhosa, their home language, than it did in their first additional language, English. This might be due to the fact that translanguaging plays a facilitative role in sense-making in which readers utilises their entire linguistic repertoire to decipher content. While a reader also brings meaning to the text in order to make more sense of it, reading involves deciphering a written linguistic code. Making sense of a text, therefore, requires a reader to relate various meanings of the text to what the reader already knows, albeit in a different language.

In order to make relevant predictions from a reading text, a reader relies on salient textual cues and background knowledge. Therefore, the readers' pre-existing knowledge, related to the text content, plays a pivotal role. Prior knowledge helps readers compensate for gaps in text-based information by affording quick and relatively effortless access to relevant information in long-term memory, based on incomplete text-based information as cues. While the results showed that the participants exhibited improved performance with regard to text prediction, the quality of the English responses exhibited that the participants could not provide the expected correct answers due to lack of adequate linguistic knowledge. The ability to make predictions and express them in an additional language might be a cognitively demanding task for a Grade 4 learner, hence the relatively deficient performance in English. One of the reasons advanced to this effect, is that at Grade 4 learners are still at the elementary stages of acquiring the additional language, and, in some cases, the so-called home language, and thus have not yet established a solid linguistic arsenal from which to draw when attempting to clearly express thoughts. Nonetheless, the groups that received the translanguaging intervention, which were the first and the second experimental groups, displayed an improved performance in the said skill due to the intervention. It would be more interesting to find out how the participants would have performed if they had been allowed to use their home language to respond to English questions in the actual test, as was the case during the intervention in which they received input in one language and gave output in another. The current practice in assessment unfortunately prevents such an exercise from being effected: a test-taker is expected to respond to questions in the language in which the questions have been asked.

\section{Acknowledgements Competing interests}

The author declares that they have no financial or personal relationships that may have inappropriately influenced them in writing this article.

\section{Authors' contributions}

V.D.M. declares that they are the sole author of this research article.

\section{Funding information}

This research received no specific grant from any funding agency in the public, commercial or not-for-profit sectors. 


\section{Data availability}

The author confirms that the data supporting the findings of this study are available within the article.

\section{Disclaimer}

The views and opinions expressed in this article are those of the author and do not necessarily reflect the official policy or position of any affiliated agency of the author.

\section{References}

Allbritton, D., 2004, 'Strategic production of predictive inferences during comprehension', Discourse Processed 38(3), 309-322. https://doi.org/10.1207/ s15326950dp3803_2

Baker, C., Jones, B. \& Lewis, G., 2012, 'Translanguaging: Origins and development from school to street and beyond', Educational Research and Evaluation 18(7), 641-654. https://doi.org/10.1080/13803611.2012.718488

Block, C.C. \& Duffy, G.G., 2008, 'Research on teaching comprehension: Where we've been and where we're going', in C.C. Block \& S.R. Parris (eds.), Comprehension instruction: Research-based best practices, 2nd edn., pp. 18-37, Guilford Publications, New York, NY.

Department of Basic Education (DBE), 2014, Annual national assessment diagnostic report - First additional language and home language, Department of Basic Education.

Duke, N.K. \& Pearson, P.D., 2004, 'Effective practices for developing reading comprehension', in A. Farstrup (ed.), What research has to say about reading instruction, pp. 205-242, International Reading Association, Inc., Newark, NJ.

García, O., 2009, Bilingual education in the 21st century: A global perspective, Wiley/ Blackwell, Malden, MA
Goodman, K.S. \& Goodman, Y.M., 1976, 'Reading: A psycholinguistic guessing game', in K.S. Goodman \& Y.M. Goodman (eds.), Making sense of learners of written language. The selected works of Kenneth S. Goodman and Yetta M. Goodman, language. The selected works of Kenn
pp. 103-112, Routledge, New York, NY.

Hornberger, N.H. \& Link, H., 2012, 'Translanguaging and transnational literacies in multilingual classrooms: A biliteracy lens', International Journal of Bilingud Education and Bilingualism 15(3), 261-278. https://doi.org/10.1080/13670050.2 012.658016

Howie, S., Combrinck, C., Roux, K., Tshele, M., Mokoena, G. \& Palane, N.M., 2017, Progress in international reading literacy study 2016: South African children's reading literacy achievement, Centre for Evaluation and Assessment, University of Pretoria, Pretoria.

Makalela, L., 2016, 'Ubuntu translanguaging: An alternative framework for complex multilingual encounters', Southern African Linguistics and Applied Language Studies 34(3), 187-196. https://doi.org/10.2989/16073614.2016.1250350

Mclntyre, E., Hulan, N. \& Layne, V., 2011, Reading instruction for diverse classrooms Research-based, culturally responsive practice, The Guilford Press, London.

Modisaotsile, B.M., 2012, The failing standard of basic education in South Africa, Policy Brief, Briefing 72, Africa Institute of South Africa (AISA), Pretoria.

Readability Formulas, 2017, Readability formulas, viewed 30 June 2017, from http:// www.readabilityformulas.com/freetests/six\%ADreadability\%ADformulas.php.

Roit, M.L., 2016, 'Effective teaching strategies for improving reading comprehension in K-3 students', Open Court Reading, viewed 15 October 2018, from https:// www districtadministration.com/sites/districtadministration/files/sites/ districtadministration/files/resources/improving_reading_3.pdf.

Van Dyk, H. \& White, C., 2019, 'Theory and practice of the quintile ranking of schools in South Africa: A financial management perspective', South African Journal of Education 39(1), 1-9. https://doi.org/10.15700/saje.v39ns1a1820

Vogel, S., Ascenzi-Moreno, L. \& García, O., 2018, 'An expanded view of translanguaging: Leveraging the dynamic interactions between a young multilingual writer and machine translation software', in J. Choi \& S. Ollerhead (eds.), Plurilingualism in teachingand learning: Complexities across contexts, pp. 89-106, Taylor \& Francis Ltd., London.

Wei, L., 2018, 'Translanguaging as a practical theory of language', Applied Linguistics 39(1), 9-30. https://doi.org/10.1093/applin/amx039 